\title{
Primary Synovial Sarcoma of the Lung with Intra-Cardiac Extension
}

\author{
Veena S. Devarakonda ${ }^{\mathrm{a}} \quad$ Larissa Lembert $^{\mathrm{b}} \quad$ John W. Entwistle, III ${ }^{\mathrm{c}}$ \\ Jeffrey B. Hoag a, d \\ ${ }^{a}$ Division of Pulmonary, Critical Care and Sleep Medicine, ${ }^{b}$ Department of Medicine and Pathology, and \\ 'Department of Cardiothoracic Surgery, Drexel University College of Medicine, and d Cancer Treatment Centers of \\ America, Eastern Regional Medical Center, Philadelphia, Pa., USA
}

\section{Established Facts}

- Pulmonary synovial sarcomas are very rare tumors and account for less than $0.5 \%$ of all intrathoracic neoplasms.

\section{Novel Insights}

- This is the first description of pulmonary synovial sarcoma with direct intra-cardiac extension.

\section{Key Words}

Synovial sarcoma, pulmonary • Extension, intra-cardiac • Neoplasm, intra-thoracic

\begin{abstract}
Synovial sarcomas are a distinct clinical entity occurring most often in the lower extremities. They account for 10$14 \%$ of all soft tissue sarcomas. Pulmonary synovial sarcomas are quite rare and account for less than $0.5 \%$ of all intra-thoracic neoplasms. We present the first reported case of primary pulmonary synovial sarcoma with intra cardiac extension in a 53-year-old male who presented with chronic cough. Imaging revealed a large right upper lobe mass extending through the superior pulmonary veins into the left
\end{abstract}

atrium. The patient underwent a right total pneumonectomy with extraction of the left atrial mass and left atrial reconstruction. Pathology and immunohistochemistry was diagnostic of primary pulmonary synovial sarcoma positive for SYT-SSX1 gene fusion transcription.

Copyright $\odot 2010$ S. Karger AG, Basel

\section{Introduction}

Pulmonary sarcomas are typically metastatic foci as the lung is the most common site of distant organ spread of mesenchymal neoplasms. Primary pulmonary sarcomas are quite rare, representing less than $0.5 \%$ of all intrathoracic neoplasms [1]. Synovial sarcomas are a distinct

\section{KARGER}

Fax +41613061234

E-Mail karger@karger.ch

www.karger.com
(C) 2010 S. Karger AG, Basel

$0025-7931 / 11 / 0813-0249 \$ 38.00 / 0$

Accessible online at: www.karger.com/res
Veena S. Devarakonda, MD

Division of Pulmonary, Critical Care and Sleep Medicine

Drexel University College of Medicine, 245 N. 15th St., Mail Stop 107, NCB 12th Floor Philadelphia, PA 19102 (USA)

Tel. +1 215762 7011, Fax +1 215762 8728, E-Mail presh76@ gmail.com 
Fig. 1. a Transesophageal echocardiogram demonstrating a large mass (arrow) in the left atrium (LA). b Chest radiograph demonstrating large right upper lobe mass adjacent to the mediastinum. c MRI depicting the right upper lobe mass extending into the left atrium (arrow).
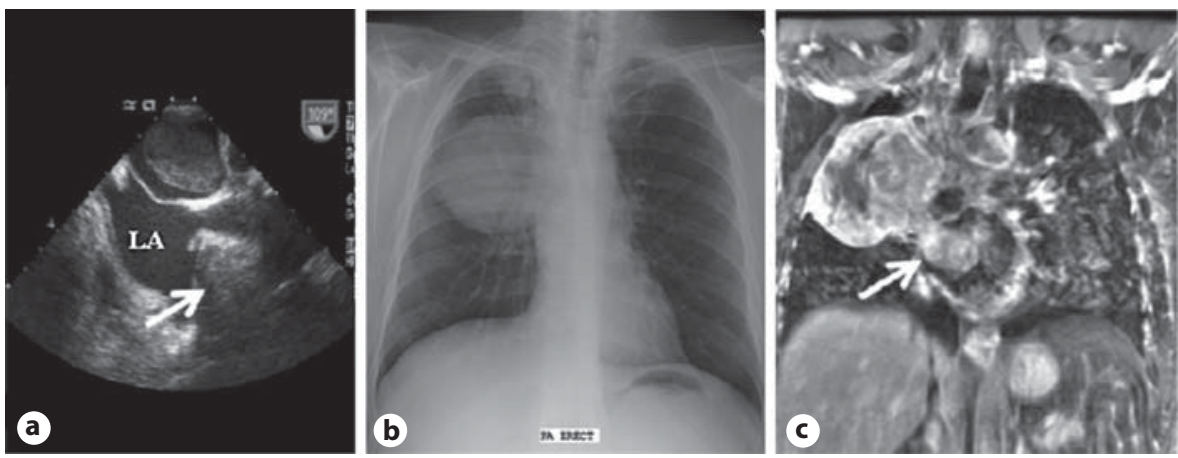

Fig. 2. a Gross specimen sectioned from right pneumonectomy. b Low-power image $(10 \times)$ of tumor. $\mathbf{c}$ Vimentin staining of specimen confirming synovial sarcoma origin. d High-power image $(100 \times)$ showing active mitotic figures in synovial sarcoma.
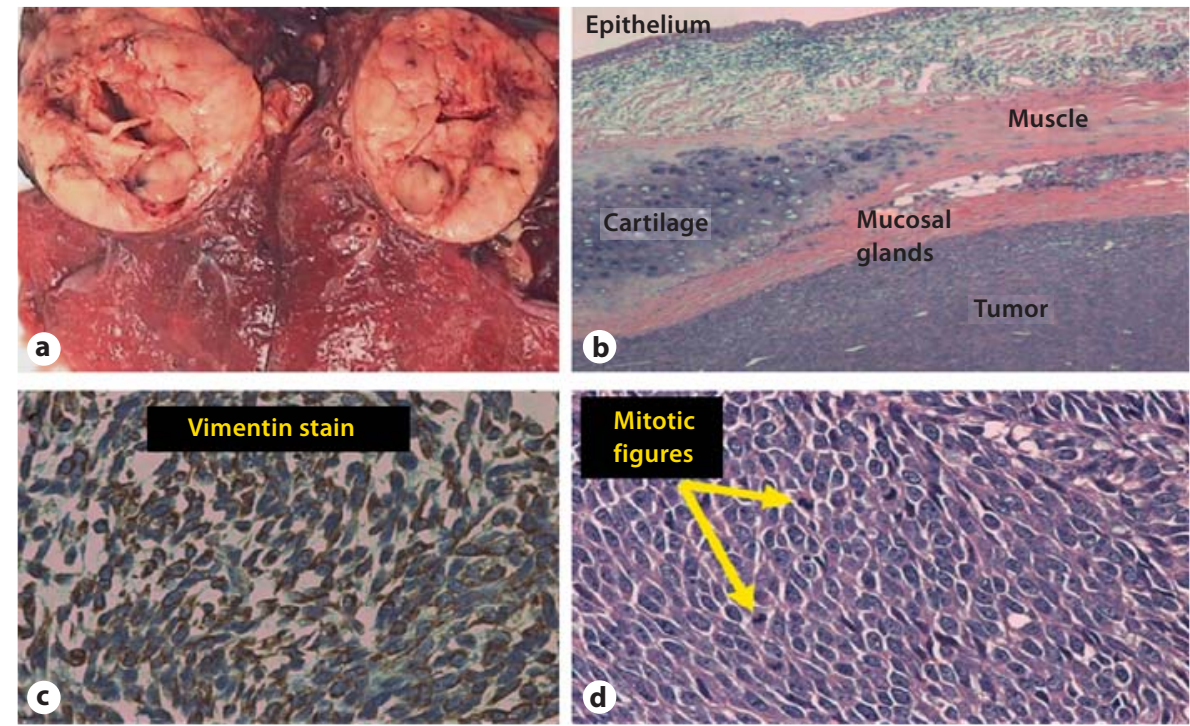

clinical entity occurring most often in the lower extremities and less so at other sites, and account for $10 \%$ of all soft tissue sarcomas [2]. Although synovial sarcoma has microscopic resemblance to normal synovium, it is differentiated from synovium based upon staining for epithelial markers including cytokeratin or epithelial membrane antigen. Primary pulmonary synovial sarcoma (PPSS) is extremely rare, but the occurrence of this tumor is being increasingly recognized [3-12]. Herein, we present the first description of primary pulmonary synovial sarcoma with direct intra-cardiac extension.

\section{Case Report}

A 53-year-old nonsmoking male treated with mantle radiation for Hodgkin's lymphoma 13 years ago presented with 6 weeks of nonproductive cough. He denied dyspnea, chest pain, palpitations, and he ran 3 miles on a treadmill daily without limitation. Physical examination was notable for diminished breath sounds in the right upper chest. Heart exam was normal. Echo- cardiogram was obtained based on suspicious findings of his invasive studies. It revealed a large left atrial mass $(4.4 \times 2.6 \mathrm{~cm})$ originating from the right superior pulmonary vein which traversed the mitral valve causing moderate mitral regurgitation (fig. 1a). Pulmonary function testing demonstrated mild restriction and a normal diffusing capacity. Chest radiograph demonstrated a large round opacity in the right upper lobe $(10 \times 9 \mathrm{~cm})$ adjacent to the mediastinum (fig. lb). MRI demonstrated the right upper lobe mass with invasion of the right superior pulmonary vein and left atrium (fig. 1c). A computed tomography-guided needle biopsy was suspicious for synovial sarcoma based on histopathology and immunohistochemistry. PET-CT was negative for metastatic spread. The patient subsequently underwent bilateral anterior thoracotomy (clamshell) incision and was placed on cardiopulmonary bypass so that the intracardiac portion of the tumor could be addressed first to minimize the risk of tumor embolization. The left atrium was opened and the intraatrial portion of the tumor removed. The atrium was reconstructed and the patient was weaned from bypass support. He then underwent a right pneumonectomy with resection of the tumor. There was a large mass in the upper and middle lobes of the lung, and the lung was adherent to the chest wall medially and apically. The medial adhesions appeared to be from prior radiation therapy for Hodgkin's disease while the apical adhesions 
later returned suspicious for sarcoma. Gross examination of the right lung revealed a well circumscribed tan, white soft mass ( 8 $\times 8 \times 7.5 \mathrm{~cm})$ with focal areas of necrosis. The intracardiac mass was oval-shaped nodular tissue with a smooth surface $(7 \times 3 \times$ $2 \mathrm{~cm}$ ) and weighed $28 \mathrm{~g}$. The surgical margin of the resected tumor was negative. Microscopically, the tissue stained positive for vimentin, BCL-2 and epithelial membrane antigen, diagnosing monophasic pulmonary synovial sarcoma (fig. 2). CD 99 was negative and epithelial membrane antigen was focally positive. Molecular studies performed on submitted tissue were positive for the SYT-SSX gene.

The patient had an uneventful hospital course and was discharged 1 week postoperatively. Although ifosfamide was considered, he subsequently underwent adjuvant chemotherapy with CYVADIC (cyclophosphamide, vincristine, doxorubicin and dacarbazine) regimen because of easier dosing schedule. He died 18 months after surgical resection because of sarcoma recurrence in his abdomen. There was no recurrence in his chest.

\section{Discussion}

Synovial sarcomas are soft tissue tumors of uncertain histogenesis, occurring usually in the lower extremities. Rarely they have been described in the head/neck, chest and abdomen [11]. Pulmonary sarcomas are rare $(<0.5 \%$ of lung tumors) and are usually metastases from other primaries (leiomyosarcomas, fibrosarcomas and hemangiopericytomas) [1]. Usually they present as well defined masses of variable size $(2-15 \mathrm{~cm})$ in an asymptomatic patient found on routine X-ray. In the previously reported 75 cases, the masses were situated in every lobe of the lung, some with pleural involvement and effusions. Rare cases of endobronchial extensions have also been reported. Herein we report the first case of synovial sarcoma with an intra cardiac extension. Histologically, they are classified into four subtypes: biphasic, monophasic fibrous, monophasic epithelial, and poorly differentiated [13]. These tumors stain frequently for epithelial markers such as cytokeratin and/or epithelial membrane antigen, vimentin and CD99. Diagnosis can be made on clinical, histological and immunohistochemical evaluation, and molecular testing is not required in all cases although it might help portend prognosis [14]. Clinical course is variable with a mortality rate of up to $55 \%$ from one series of 25 patients who had follow up from 1-20 years [15].

Theoretically, all tissue exposed to radiation is at risk for undergoing malignant transformation at some time in the future. The Late Effects Study Group cohort (Hodgkin's disease as the primary malignancy) reported a $10.6 \%$ incidence of second malignant neoplasm at 20 years and $26.3 \%$ incidence at 30 years of follow up [16]. Ng et al. pro- vided data showing an escalating risk of developing a second malignant neoplasm at extended follow up [17]. After radiation therapy was given for Hodgkin's disease, they found a $2.3 \%$ excess risk of developing a second malignant neoplasm per year at 15 years of follow-up and a $4 \%$ excess risk per year at 20 years [17]. Of the nearly 60 cases reported in literature, only 11 have described the definitive molecular detection of SYT-SSX fusion gene transcription [3-10]. The function of the fusion protein remains uncertain: the SYT protein appears to function as a transcriptional activator, whereas the SSX protein appears to function as a transcriptional co-repressor. It is not known if one or both functions persist in the fusion protein. The $\mathrm{T}(\mathrm{X} ; 18)(\mathrm{p} 11.2 ; \mathrm{q} 11.2)$ translocation results from fusion of the SYT gene on chromosome 18 to either SSX1 or SSX2 on chromosome X. SYT-SSX1 has a worse prognosis, with a 5 -year survival rate of $42 \%$, versus $89 \%$ for SSX2 $[18,19]$. The prognostic relevance of SYT-SSX1 or -SSX2 translocation remains controversial as a number of the more recent publications dispute its impact. The more important prognostic determinants of SS are subtype and resectability of the tumor.

\section{Conclusion}

This report is the first case of primary pulmonary synovial sarcoma with direct intra-cardiac extension. Given the extent of cardiac involvement, MRI and echocardiography were useful diagnostic modalities prior to surgical intervention. Although we cannot make a general statement regarding their routine use, it does seem worthwhile to consider these modalities given the rarity of these tumors and their unusual locations. Gene testing may provide adjunctive prognostic information.

\footnotetext{
References Travis WD, Travis LB, Devesa SS: Lung cancer. Cancer 1995;75:191-202.

$\checkmark 2$ Cadman NL, Soule EH, Kelly PJ: Synovial sarcoma: an analysis of 134 tumors. Cancer 1965;18:613-627.

3 Roberts CA, Seemayer TA, Neff JR, Alonso A, Nelson M, Bridge JA: Translocation (X; 18) in primary synovial sarcoma of the lung. Cancer Genet Cytogenet 1996;88:49-52.

-4 Kaplan MA, Goodman MD, Satish J, Bhagavan BS, Travis WD: Primary pulmonary sarcoma with morphologic features of monophasic synovial sarcoma and chromosome translocation t(X; 18). Am J Clin Pathol 1996; 105:195-199.
} 
5 Hisaoka M, Hashimoto H, Iwamasa T, Ishikawa K, Aoki T: Primary synovial sarcoma of the lung: report of two cases confirmed bymolecular detection of SYT-SSX fusion gene transcripts. Histopathology 1999;34:205210.

-6 Sekeres M, Vasconcelles MJ, McMenamin M, Rosenfeld-Darling M, Bueno R: Two patients with sarcoma. Case 1 . Synovial cell sarcoma of the lung. J Clin Oncol 2000;18: 2341-2342.

$>7$ Terasaki H, Niki T, Hasegawa T, Yamada T, Suzuki K, Kusumoto M, et al: Primary synovial sarcoma of the lung: a case report confirmed by moleculardetection of SYT-SSX fusion gene transcripts. Jpn J Clin Oncol 2001;31:212-216.

$>8$ Hummel P, Yang GC, Kumar A, Cohen JM, Winkler B, Melamed J, et al: PNET-like features of synovial sarcoma of the lung: a pitfallin the cytologic diagnosis of soft-tissue tumors. Diagn Cytopathol 2001;24:283-288.

$\checkmark 9$ Fadare O, Ciesielski T: Pathologic quiz case: a pulmonary mass. Arch Pathol Lab Med 2003;127:e160-e162.
10 Mikami Y, Nakajima M, Hashimoto H, Kuwabara K, Sasao Y, Manabe T: Primary poorly differentiated monophasic synovial sarcoma of the lung. A case report with immunohistochemical and genetic studies. Pathol Res Pract 2003;199:827-833.

11 Boroumand N, Raja V, Jones DV, Haque AK: SYT-SSX2 variant of primarypulmonary synovial sarcoma with focal expression of CD117(c-Kit) protein and a poor clinical outcome. Arch Pathol Lab Med 2003;127:201204.

12 Niwa H, Masuda S, Kobayashi C, Oda Y: Pulmonary synovial sarcoma with polypoid endobronchial growth: a case report, immunohistochemical and cytogenetic study. Pathol Int 2004;54:611-615.

13 Enzinger FM, Weiss SW: Soft Tissue Tumors, ed 3. St. Louis, Mosby Year Book, 1995, pp 757-786.

14 Coindre JM, Pelmus M, Hostein I, Lussan C, Bui BN, Guillou L: Should molecular testing be required for diagnosing synovial sarcoma? A prospective study of 204 cases. Cancer 2003;98:2700-2707.

-15 Zeren H, Moran CA, Suster S, Fishback NF, Koss MN: Primary pulmonary sarcoma with features of monophasic synovial sarcoma: a clinicopathological, immunohistochemical, and ultrastructural study of 25 cases. Hum Pathol 1995;26:474-480.
6 Bhatia S, Yasui Y, Robison LL, Bogue MK, Diller L, DeLaat C, Fossati-Bellani F, Morgan E, Oberlin O, Reaman G, Ruymann FB, Tersak J, Meadows AT, Late Effects Study Group: High risk of subsequent neoplasms continues with extended follow-up of childhood Hodgkin's disease: report from the Late Effects Study Group. J Clin Oncol 2003; 21:4386-4394.

$17 \mathrm{Ng} \mathrm{AK}$, Bernardo MP, Weller E, Backstrand KH, Silver B, Marcus KC, Tarbell NJ, Friedberg J, Canellos GP, Mauch PM: Long-term survival and competing causes of death in patients with early-stage Hodgkin's disease treated at age 50 or younger. J Clin Oncol 2002;20:2101-2108.

18 Kawai A, Woodruff J, Healey JH, Brennan MF, Antonescu CR, Ladanyi M: SYT-SSX gene fusion as a determinant of morphology and prognosis insynovial sarcoma. N Engl J Med 1998;338:153-160.

19 Nilsson G, Skytting B, Xie Y, Brodin B, Perfect R, Mandahl N, et al: The SYT-SSX1 variant of synovial sarcoma is associated with a high rate of tumor cell proliferation and poor clinical outcome. Cancer Res 1999;59:31803184. 